\title{
ARTIGOS
}

\section{A EXPERIÊNCIA ESTÉTICA EM TEMPOS DE VIRTUALIZAÇÃO TECNOLÓGICA}

ELAINE CONTE • CATIA PICCOLO VIERO DEVECHI

\section{RESUMO}

O ensaio busca problematizar os sentidos da arte e das tecnologias na racionalidade pedagógica, a partir dos elementos da teoria crítico-estética de Theodor Adorno. Para isso, lançamos as seguintes questões: Em plena era digital, ainda faz sentido pensar na experiência formativa da arte? É possível desmistificar as tecnologias na educação pela reconstrução estética de significados? Como pensar a dimensão expressiva da educação no âmbito da instrumentalidade? Por meio de um estudo hermenêutico, buscamos compreender e repensar as tecnologias, discutindo uma mediação crítica do universo da arte na educação, enquanto gesto reflexivo, intercâmbio dialógico e emancipatório, ao mesmo tempo possível e bloqueado pelas relações opostas e intensas da atualidade.

EDUCAÇÃO • TECNOLOGIA • EXPERIÊNCIA • ESTÉTICA

\section{THE AESTHETIC EXPERIENCE IN TIMES OF TECHNOLOGICAL VIRTUALIZATION}

\section{ABSTRACT}

This essay attempts to problematize the meaning of art and technologies in the educational rationale, based on the elements of the critical aesthetic theory of Theodor Adorno. For this, we raise the following issues: Does it still make sense to think about the formative experience of art within the digital age? Is it possible to demystify the technologies of education through the aesthetic reconstruction of meanings? How can we consider the expressive dimension of education within the scope of instrumentality? Through a hermeneutic study, we seek to understand and rethink technologies, discussing a critical mediation of the universe of art in education, as a reflexive gesture, a dialogical and emancipatory exchange, at the same time made possible and yet hindered by the opposing and intense relationships of today. 


\section{L'EXPÉRIENCE ESTHÉTIQUE À L'ÉPOQUE DE VIRTUALISATION TECHNOLOGIQUE}

RÉSUMÉ

Cet essai vise à problématiser la question du sens de l'art et des technologies au sein de la rationalité pédagogique, à partir des éléments de la théorie critique et esthétique de Theodor Adorno. A ce fin, nous posons les questions suivantes : à l'âge de la numérisation, il y a-t-il encore un sens de penser à l'expérience formative de l'art? Est-il possible de démystifier les technologies dans le domaine de l'éducation par le biais d'une reconstruction esthétique du sens? Comment peut-on penser la dimension expressive de l'éducation dans la sphère de l'instrumentalité? A travers une étude herméneutique, on cherche ici à comprendre et à repenser les technologies dans l'éducation, à la lumière d'une médiation critique de l'univers de l'art, cette dernière étant prise comme geste de réflexion et comme échange dialogique et émancipatoire, à la fois possible et bloqué par les rapports conflictuels et intenses de l'actualité.

ÉDUCATION • TECHNOLOGIE • EXPÉRIENCE • ESTHÉTIQUE

\section{LA EXPERIENCIA ESTÉTICA EN TIEMPOS DE VIRTUALIZACIÓN TECNOLÓGICA}

RESUMEN

El ensayo busca cuestionar los significados del arte y de las tecnologías en la racionalidad pedagógica, a partir de los elementos de la teoría crítico-estética de Theodor Adorno. Con este fin, hemos lanzado las siguientes preguntas: En plena era digital, ¿todavía tiene sentido pensar en la experiencia formativa del arte? ¿Pueden ser desmitificadas las tecnologías en la educación por la reconstrucción estética de significados? ¿Cómo pensar la dimensión expresiva de la educación dentro de la instrumentalidad? A través de un estudio hermenéutico, hemos tratado de entender y repensar las tecnologías, discutiendo una mediación crítica del mundo del arte en la educación, en cuanto gesto reflexivo, intercambio dialógico y emancipador, al mismo tiempo posible y bloqueado por las relaciones opuestas e intensas en la actualidad. 


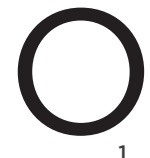

Para Adorno (2009, p. 33) depois do fracasso e dos obstáculos de modificar o mundo pela práxis sofremos um processo de especialização por meio da distância crescente em relação à experiência prática do mundo (desprovida do pensar pelas amarras do mercado e em conformação técnica). Assim, "o argumento especializado degenera-se em técnica de especialistas desprovidos de conceitos [...] passíve de ser apreendida e copiada por robôs".

S GRANDES INTELECTUAIS QUE CONSEGUIRAM EXPRESSAR DE FORMA MAIS ELABORADA os problemas das respectivas fases de desenvolvimento da humanidade tiveram sua prática entrelaçada às ambiguidades educativas, no desafio de pensar uma obra em constante movimento, pois estabeleceram discussões imanentes à produção cultural, social e à modificação institucional, identificando as inter-relações. Ao tecer conexões formativas com a arte de educar por teias antagônicas e semelhanças, propiciamos outros olhares sensíveis e percepções diferenciadas, que causam resistências às obviedades impensadas do cotidiano. É um desafio que vem ao encontro de uma necessidade de estudo para aprofundar os conhecimentos sobre o letramento crítico-tecnológico e as implicações para a aprendizagem com essas práticas nos processos de interação social. O uso da tecnologia não pode tutelar ou absolutizar o processo de formação sem levar em consideração a lógica do desenvolvimento humano, que consiste na abertura ao outro, às modalidades sensoriais de reapresentar o mundo e à curiosidade instigada pelas tecnologias, enquanto expressão criativa, prática social e dialógica.

No que segue, o debate assume o sentido de uma interpretação crítico-dialógica, segundo a qual é possível ultrapassar os limites das justificações técnicas e científicas da educação semiformativa, utilizando-se da experiência estética como possibilidade de gerar formas de resistência e integração crítica na práxis. ${ }^{1}$ Adorno ${ }^{2}$ verifica na arte o último reduto (libertador/emancipador) contra a perpetuação da exploração, alienação, desativação da história em nossas sociedades modernas, 
apesar do risco que corre toda obra de arte contemporânea de ser transformada em mercadoria pela indústria cultural e originar um estado de dispersão e alienação social, tal como acontece quando apaziguamos ou naturalizamos as tecnologias. Daí que a arte traz, em seu cerne, a resistência política na transformação dos aspectos sombrios e destrutivos da técnica em instrumento emancipatório de mudança social. Para o autor, a arte "é a antítese social da sociedade", especialmente pela sua capacidade de crítica à razão administrada, objetificadora e massificadora (ADORNO, 1992, p. 14). Por essa razão, a experiência estética possibilita o conhecimento daquilo que é excluído pela lógica moderna, no sentido de compreender o movimento de constituição e desdobramento da arte, através de correlações com a práxis social, que mostram o caráter vivaz e imprevisível da obra artística.

A partir do Renascimento, presenciamos a desvalorização, o esquecimento e até mesmo a vulgarização do real sentido do conceito aristotélico de imitação, ${ }^{3}$ que indicava o poder de autonomia dos sujeitos na produção do conhecimento, na capacidade de fazer relações. Para Adorno (1992a), o processo expressivo é constitutivo da obra de arte e só ocorre realmente na presença da realização plena de uma linguagem comunicacional (nas metáforas e imagens), capaz de transformar a própria vida em obra no âmago da realidade. A formação estética é, para o autor, o único meio consistente para negar e criticar as condições materiais e sociais de vida e restabelecer a dialética da racionalidade na multiplicidade do real. Daí que a alteridade e a irredutibilidade da arte aos condicionamentos de qualquer natureza evidenciam o seu caráter hermenêutico, ${ }^{4}$ no sentido de que a sua interpretação é não algo secundário ao seu acabamento, mas sim um aspecto constitutivo de sua própria gênese, imanente à arte e à virtualidade da linguagem. De Kant a Adorno, a dimensão estética (nível pré-discursivo) exerceu a função de reaproximação entre sujeito e objeto, resistindo ao enquadramento da representação e permitindo a reconciliação dos distanciamentos do conhecimento, como contrapartida da dominação técnica efetuada pelo homem sobre a natureza. Mas a arte, assim como os artefatos técnicos, necessita de permanente autocorreção ideológica, ${ }^{5}$ pois brota de comportamentos práticos e modifica-se no contexto de novas contradições sociais enquanto uma forma de ação ambígua e paradoxal na polis.

Segundo Adorno (1992a, p. 45), a arte serve como antítese "da passagem do interesse estético da subjetividade comunicativa para a consonância do objeto, algo de qualitativamente outro", que liberta o homem das amarras dos sistemas desumanos e o coloca como um ser autônomo, e, portanto, um ser humano livre para pensar, sentir e agir. Já que, para a indústria cultural, o homem é mero objeto de trabalho e consumo, vivendo sempre insatisfeito, colonizado e querendo consumir, tendo sua mola propulsora no desejo de posse frequentemente
3

O termo mimese, na tradição aristotélica, designa o processo estético de composição do mito que não é cópia ou reprodução do real, mas algo capaz de recriar cognitivamente, reconhecer e elevar o existente através de novas interpretações e correlações. Cf. PALHARES, Carlos V. T. A mimese na poética de Aristóteles. Cadernos Cespuc de Pesquisa, Belo Horizonte n. 22, 2013. Disponível em: <http://periodicos. pucminas.br/index.php/ cadernoscespuc/article/ view/8113>. Acesso em: 20 set. 2015 .

4 Hermeneuticamente falando podemos dizer que o autor é um homem virtualmente morto, porque passa a viver apenas do que está escrito. Mas o texto foge ao controle do autor(a) uma vez que suscita no intérprete outros sentidos e significados que vão além do escrito, descobrindo novos potenciais criadores.

5 Para Adorno (1993, p. 36-37), a cultura como ideologia é entendida como falsa consciência, de aparência comum aos intelectuais burgueses e a seus adversários, Nietzsche e Marx, que tendem a submeter tudo ao mercado capitalista, inclusive todas as relações humanas (isolando e fragilizando o indivíduo do contato ativo com o social), tornando elas próprias ideologias da falsidade irrefletida, de interesse material e lógica utilitarista, de amor ilusório. Adorno enuncia o aforismo de jogar "a criança com a água do banho" para tecer críticas à cultura, pois simula uma inexistente sociedade digna e igualitária, que serve para manter as condições reprimidas e fetichizadas como apaziguamento para manter viva a desigual determinação econômica da crescente barbárie. 
renovado pelo progresso técnico e científico, o pensar estético mantém viva a experiência do imigrante, que torna reconhecível o ato criativo (do aprender mimético) e o diálogo de reconciliação com o outro. A educação é vista por Adorno (1995) como uma possibilidade de manter-se aberto, para o discurso alheio, com todos os sentidos que recompõem a pluralidade e a humanidade como função decisiva da arte de educar. A prática pedagógica seria um misto de ciência e arte e cujo papel reúne a investigação e a transmissão dos conhecimentos produzidos não como algo neutro, mas como um processo de transformação das relações técnicas e sociais que penetra os processos educativos. Daí que o progresso das novas tecnologias, assim como o aumento das oportunidades educacionais, não resultou em avanço na humanização ou formação, pois a simples reprodução da realidade precisa dar lugar a um vasto horizonte autorreflexivo sobre a vida social, que constitui seu elemento vital como uma força estética produtiva e que pode provocar o sofrimento humano enquanto dificulta sua expressão formativa: “A arte é assim, para o sujeito, metamorfoseada no que ela é em si, porta-voz histórico da natureza oprimida e, em última análise, crítica perante o princípio do eu, agente interno da opressão" (ADORNO, 1992a, p. 370).

A "educação tem sentido unicamente como educação dirigida a uma autorreflexão crítica”, sendo que o agir comunicativo traz consigo uma contínua expressão e (re)construção cultural (ADORNO, 1995, p. 121). Isso significa que, mesmo inseridos nos processos de semiformação das relações humanas reificadas pela realidade funcional, podemos buscar um arcabouço substancial de resistência para as relações danificadas da práxis política: "Aqui tem seu lugar a ideia da arte como reconstituição da natureza oprimida e implicada na dinâmica histórica” (ADORNO, 1992a, p. 152). Por meio da arte, os sujeitos da educação ampliariam a sua capacidade de reflexão e percepção crítica da realidade, assim como sua sensibilidade no processo de humanização.

Partindo dos pressupostos educativos da teoria estética de Adorno, buscamos discutir a possibilidade de articular a estética e as tecnologias na educação, tendo em vista que essas últimas são percebidas de maneira radicalmente diferente das velhas técnicas, pois agora vêm enlaçadas a imagens de mundo coletivamente partilhadas, som, escrita, espacialidade e intercomunicação, mimetizando significados, desvelando sintomas de uma sociedade hipertextualizada e hipersensibilizada, fugindo ao controle da linha de montagem, mas, ao mesmo tempo, gerando dispersão e hiperatividade nos sujeitos. Primeiramente, apresentamos o entendimento da arte e da tecnologia como formas de percepção do mundo e como parte da cultura experimentada pelos sentidos (marcada pelo entusiasmo pelos novos meios técnicos), num universo de situações inusitadas, que requerem uma educação para pensar e agir com autonomia e poder aprender de modo diferente. Em 
seguida, analisamos em que medida a experiência formativa da arte, em plena era digital, pode surgir como recurso para desmistificar as tecnologias na educação pela reconstrução estética. O pano de fundo gira em torno da contradição dialética que propõe repensar a dimensão expressiva do saber educativo como uma obra inacabada - uma forma mimética de aprendizagem e, ao mesmo tempo, como um sintoma da razão instrumentalizada.

\section{REPENSANDO A ARTE E AS TECNOLOGIAS}

O tema da estética adorniana volta ao cenário sobretudo quando uma obra educativa repleta de tensões, como é o campo da virtualização tecnológica, enreda-se em autoilusões sociais (pureza da técnica como insuspeitado espaço de liberdade), representando meramente a pedagogização e a mecanização (incompreensão) da expressividade na formação cultural (ADORNO, 1992a). Nos moldes vigentes, a educação é mobilizada pelo paradigma objetivista do saber produtivo e homogêneo (um saber de vidro e estático na visão de mundo), que gera sujeitos solitários, para interferir tecnicamente com sucesso no controle padronizado dos conhecimentos. A educação torna-se cada vez mais instância legisladora da ação, resultando em atitudes frias, mecânicas e fragmentadas, reveladas nos limites da razão instrumental, sem sentido e significado para as relações humanas, retirando a capacidade de reflexão crítica do próprio sujeito enquanto agente de pesquisa e recriador de conhecimentos. Assim, a alteridade e o próprio diálogo autocrítico são negados porque a simples existência do outro é fonte de angústia e desvinculação. Nesse contexto, questionamos, com Adorno (1995), como pensar numa perspectiva de educação que permita fazer associações acerca da relação dialética entre a arte e a tecnologia, a comunicação e a informação, a objetividade, a subjetividade e a intersubjetividade. Para Adorno, esse tipo de coisa só seria possível mediante esforço espontâneo e interesse pela emancipação, a partir de uma visão integradora de mundos, como forma de enfrentar a separação entre o conhecimento racional e as sensibilidades, entre pensar e sentir, para que a formação seja ela mesma autoformação, atuando sobre a humanidade como um todo, e não agindo apenas nos indivíduos isolados. Afinal, 
Com isso, Adorno denuncia que a anulação do indivíduo reflete o processo social, cuja meta de realização acontece pelo isolamento e falso sentimento de autossuficiência, que penetra a realidade. Adorno reconhece, pelo ponto de vista estético, as bases e as implicações dessa problemática, vendo na participação em manifestações culturais a possibilidade de uma realização plenamente humana. No entanto, essas manifestações da vida social exigem a reflexão sobre a experiência da vida danificada, porque podem contribuir para a alienação e retroalimentação da injustiça e da dominação, que envolve toda a ação e sociabilidade humana. Sendo assim, "só a estranheza é o antídoto para a alienação" (ADORNO, 1993, p. 81). Por tudo isso, manifestamos que, em plena era digital, ainda faz sentido pensar na experiência formativa da arte como expressão linguística e reflexão crítica sobre o próprio conteúdo contraditório e instável das formulações tecnológicas na educação. Mas como compreender, resistir e manter viva a dimensão expressiva da educação no âmbito arbitrário e instrumental das formas de pensar e ver o mundo?

As tecnologias contemporâneas produzem a passagem de um tempo com regras conhecidas a um mundo instável e incerto, cujas transformações exigem repensar constantemente as distintas formas de vida. Por essa via, as tecnologias representam a invenção de novas linguagens, práticas e possibilidades de ação em nossa forma de ser e conviver no mundo, pois ressaltam a prioridade da linguagem nos processos de constituição social. As tecnologias surgem como todas aquelas conversações nas quais inventamos novas práticas de vida e ferramentas para produzir novos sentidos para a ação pedagógica. De acordo com Gadamer (1993), o problema está no fato de que os processos técnicos e econômicos do mundo contemporâneo se tornam independentes dos processos políticos e democráticos, gerando domínio universal, relação de poder, conformismo e passividade, que tendem a submeter as singularidades e as diferenças culturais. Sob essa influência, a educação passa por um processo de indefinição, instaurado pelo descompasso entre, de um lado, o reconhecimento e as implicações das novas tecnologias no espaço educativo e, de outro, a dificuldade em problematizar e reconduzir as tecnologias pesquisadas às quebras de ordenação dos processos educativos de ressignificação de conhecimentos, porque a educação fica desprovida de seu caráter contraditório (das dimensões do outro e das diferenças), servindo à mercantilização reprodutiva da cultura presente. Segundo Goergen (1996, p. 23): 
Parece que as tradições culturais e históricas que condicionam as identidades pedagógicas à coerção funcional do estar produtor e produto tendem a ser mais fortes que a vontade racional de reconhecer o ser humano como livre e autônomo, vivendo assim uma falsa liberdade, pois, nessas condições, "meio e fim veem-se confundidos" (ADORNO, 1992b, p. 7). Podemos dizer que, efetivamente, o sujeito passa de agente e relógio do mundo, ou seja, de potencialmente criativo, a ser uma simples peça de engrenagem desse grande relógio, um simples executor do trabalho. O homem guiado pela certeza do conhecimento torna-se incapaz de recriá-lo e, nessa dissolução técnica com o mundo, o sujeito fica preso à sua própria razão instrumental aniquiladora de novas relações, metamorfoses e sensibilizações. As tecnologias como sintoma de nosso tempo revelam novas práticas de mediação pedagógica e invenção de linguagens, que sustentam diferentes possibilidades de ação, alterando drasticamente a própria natureza humana. Nesse contexto, a crítica adorniana (1992b) é direcionada ao primado da práxis social não refletida, tendo em vista que a própria teoria é uma tentativa de incorporação dialética da práxis, inscrita na experiência da materialidade histórica.

Nos últimos tempos, houve uma mudança da reprodução mecânica das tecnologias para as comunicações eletrônicas no mundo, em espaços de encontro como o Facebook, ${ }^{6}$ Instagram, Telegram, Twitter, Whatsapp (mas que também manifestam deficiências, por serem algo tranquilizante para tratar nossa solidão e falta de conhecimento, diria Zygmunt Bauman), num clima de pensamento positivo, de solidariedade em tempo real. Nesse momento, a linguagem como ferramenta criadora de realidades é o principal meio para articular os novos interesses no mundo, uma vez que as tecnologias são desencadeadoras de nossa transformação cultural, mas também correm o risco de domesticar a curiosidade e alienar a linguagem. Parafraseando Adorno (1995), poderíamos dizer que, para enfrentar uma sociedade alienada, urge sensibilizar e aproveitar a inteligibilidade do sujeito, que é potencializada no ato de resistência ao conformismo resignado e no processo de autorreflexão crítica, desencadeando uma experiência compartilhada na expressividade educativa das relações dos sujeitos com suas obras e seus contextos. A experiência estética potencializa encontros com o que é estranho e diferente (o outro que nos move), guiando esforços à reinvenção da própria formação cultural na pluralidade humana. Mas qual seria o problema dessas tecnologias da comunicação na educação? Tomando a perspectiva de Adorno, podemos dizer que as armas para a emancipação cultural podem também ser instrumentos para a alienação reificante e

6

Cabe notar que inicialmente a rede social Facebook foi idealizada em 2003 para fins de relacionamento, programada para ser um jogo entre os estudantes de Harvard, mostrando aos visitantes fotos dos mais atraentes. Hoje, esse artefato não é apenas um recurso arbitrário, anestésico e que preenche o tempo livre, aliviando uma rotina maçante de trabalho, mas surge como tensão de resistência intelectual e momento de realização da transformação cognitiva e expressiva, pois serve tanto a grupos de interesses (fechados em guetos homogêneos), como para fins revolucionários e críticos de democratização de informações e bens culturais. Também é motivo de muitas pesquisas na área da educação, com potencialidades de libertação social e de redenção pela arte, mas que não podem dissociar-se ou ignorar a crítica à indústria cultural, para não recair na falsa harmonia dada às condições objetivas sociais. 
apassivada da condição humana. A partir das colocações e discernimentos de Adorno ante a experiência estética e trazendo-os para os tempos de virtualização tecnológica, refletimos que esta não possui uma essência diabólica em si (atendendo a uma panaceia universal), mas pode causar dependência cultural e letargia dos sentidos, algo mais severo que a mediação via reprodução tecnológica.

Tal reconstrução de sentido e significado desses artefatos culturais pode ser analisada sob a perspectiva do fetichismo da arte musical. Segundo Adorno (1996, p. 107), "talvez essa decadência ajude um dia a levar ao inesperado [...]. Mesmo a disciplina pode ser expressão de livre solidariedade, quando seu conteúdo for a liberdade”. Por essa visão, poderíamos repensar a virtualização tecnológica para além de qualquer valor imediato de formas isoladas, a qual nos torna, de certa forma, marionetes de seus resultados automatizados (tal qual a lógica do oráculo virtual Facebook, calculada em testes gratuitos e com conteúdos captados de uma verdade ilusória). A resistência e a potência da prática diária comunicativa com o desafio dos recursos tecnológicos na educação podem promover a real interação das tecnologias da comunicação em poder de reinvenção, reconhecimento e visibilidade crítica. Se o artista (professor) não tem obrigação de compreender a própria obra em sua totalidade, então precisa articular as inovações técnicas a partir do reflexo das condições sociais, o qual incorpora a dimensão estética de potência emancipadora (de um conteúdo crítico para a liberdade de expressão via tecnologia), manifestamente ativa e transformadora da realidade.

A educação como processo de sociabilidade e humanização é vital para a formação cultural, porque possibilita a conversação dos sujeitos no saber, no fazer e no conviver da vida, em que "atua a mesma força vital, criadora e plástica, que espontaneamente impele todas as espécies vivas à conservação e propagação do seu tipo" (JAEGER, 1995, p. 3). A educação não é uma propriedade individual, mas pertence à coletividade humana, visto que é um processo formativo desenvolvido pelos sentidos e significados inteligíveis, em conjugação com a apropriação de uma sensibilidade, que permite a percepção do saber do mundo na metamorfose do (re)aprender.

Desse modo, para resistir aos elementos de uma persistente instrumentalidade da razão no processo tecnológico, podemos repensar, em termos educativos, a sua utilização em conexão com os elementos críticos permitidos pela experiência estética. ${ }^{7}$ Por meio da estética, é pos-

Teoria estética (obra publicada em 1970, um ano após a morte de Adorno) poderia ser chamada de uma concepção estética da razão, que implica pensar numa ancoragem mimético-estética, pois a dialética do conceito é imanente a toda experiência estética. sível problematizar os processos de aprendizagem na dinâmica interna das estruturas tecnológicas, para que não sejamos vítimas de um conhecimento apenas figurado na falsificação da situação existente ou na representação da vida. Adorno vê, nas formas abertas da arte moderna (expressividade do mundo), o empenho pela maioridade (Mündigkeit) ou emancipação educativa dos esquemas de significação e das organizações 
da tradição (as identidades tornaram-se mais fluídas e emancipadas das coerções), bem como uma resposta às totalidades de sentido tradicionais de unidade harmônica da obra de arte e do sujeito. A arte, para ele, é uma dimensão intrínseca à educação, pois é uma prática realizativa, de ação performativa, e por isso seus elementos expressivos desafiam a racionalidade formativa, recuperando o sentido autônomo e contraditório do aprender, projetando novas resistências e denúncias do mundo administrado, pela possibilidade de estabelecer rupturas em relação às formas habituais de percepção, que passam pelo crivo da (auto)crítica para resolver discrepâncias e contingências vitais.

O caminho da reflexão em Adorno é analisado, em sua dialética negativa do conceito (procura contornar o que não pode expor discursivamente) e em sua teoria estética (da competência cognitiva para a arte), como um processo que ressignifica a expressividade da arte enquanto potencialidade pedagógica que eleva a capacidade de pensar, aprender e problematizar a realidade social. Adorno busca entender por que a humanidade, ao invés de realizar seus potenciais de autonomia e liberdade, caminhou em direção contrária, da mesma forma como o progresso técnico e científico não veio acompanhado de plena realização humana e do progresso da formação (Bildung). ${ }^{8}$ Desse modo, compreendemos as possibilidades performativas da educação, através de uma revisão de sentidos da própria formação, problematizando as possibilidades estéticas que atualizam a educação em sua expressividade, na busca de fazer a leitura crítica do mundo.

Assim, num mundo tecnológico que aliena os sujeitos pelo imediatismo das informações, é tarefa do educador inserir o sujeito na experiência estética permissora da leitura crítica do mundo, para não recair na violência do progresso que domina a natureza e o sujeito. A experiência estética conforme proferida por Adorno, como possibilidade de resistência, pode oportunizar a utilização da tecnologia de forma livre e autônoma. Por meio da experiência artística, é possível educar sujeitos para se contraporem à lógica massificada presente nas mídias digitais, e desfrutar desses recursos como espaço dialético de denúncia e emancipação. Certamente, a ação educativa apresenta dificuldades em readaptar-se às novas condições tecnológicas de proliferação de informações dispersivas e esvaziadas de sentido crítico. Entretanto,

[...] na medida em que transformarmos nossas práticas em exercícios reflexivos e criativos e estivermos em abertura para a comunicação, tentando não apenas dominar as tecnologias virtuais como simples ferramentas, mas como maneiras de ensaiar novas experiências culturais, estaremos participando de um novo tipo de aprendizagem social, a aprendizagem interativa que mimetiza formas reais por meio das virtuais. (MARTINI, 2005, p. 20) jogo de forças e dimensões do sujeito em relação com os outros para desenvolver-se, significando ao mesmo tempo educação, formação humanistica de valores e o comportamento pelo qual conduzimos nossas relações sociais. É um modelo alternativo de emancipação política pela razão livre e (auto)formativa que atua sobre a vida humana. Cf. SUAREZ, Rosana. Notas sobre o conceito de Bildung (Formação Cultural). Kriterion: Revista de Filosofia, Belo Horizonte, v. 46, n. 112, dez. 2005. 
Benjamin (1969) aborda a obra de arte na era da reprodutibilidade técnica e lança um olhar sobre como as percepções humanas no mundo mudaram não só por causa da natureza, mas também como consequência de fatores contingentes da evolução técnico-científica. Para o autor, a arte tem razão de ser quando consegue deixar em aberto um complexo de interpretações que desnaturalizam a realidade. Em vários momentos, identifica:

\section{[...] uma nova forma de miséria surgiu com esse monstruoso de- senvolvimento da técnica, sobrepondo-se ao homem. [...] Pois qual o valor de todo o nosso patrimônio cultural, se a experiência não mais o vincula a nós? [...] Sim, é preferível confessar que essa po- breza de experiência não é mais privada, mas de toda a humanida- de. Surge assim uma nova barbárie. (BENJAMIN, 1994, p. 115)}

As tecnologias não podem se constituir um fim em si; caso contrário, tornar-se-ão apenas mais um meio de massificação e de ocupação despreocupada, que não causa espanto nem reflexão. Com a possibilidade de computadores interligados e trabalhando simultaneamente, os sujeitos capacitam sua formação e se comunicam por estímulos, transmissão e feedback, com implicações diretas no que pensamos, sentimos e agimos. As tecnologias devem, portanto, ser exploradas por posturas questionadoras, possibilitando a aprendizagem na multiplicidade de linguagens e de interações, não no igual ou idêntico. Tal é o que a experiência estética proposta por Adorno pode proporcionar no uso midiático: uma aprendizagem comunicativa por meio de uma racionalidade interpretativa e resistente à conformação e à adaptação automatizada. Não se trata de uma vivência artística de cunho emocional apenas, mas de uma experiência crítica capaz de reconhecer, no universo de informações e relações, a possibilidade de diálogo libertador. É uma experiência estética reflexiva, que difere da experiência de cunho apenas emocional permitida pela arte. Ou seja, a arte entendida como possibilidade de negação das relações estanques e reificadas.

Diante do contexto tecnológico atual, em que a maior parte das pessoas estão conectadas, a escola não pode ficar fora do seu tempo e ignorar os recursos midiáticos de comunicação social; caso contrário, ela contribuirá para a utilização alienada desses espaços, não se servindo da potencialidade de uma aprendizagem de autoria coletiva. Entendemos que a escola precisa utilizar esses recursos como possibilidade de formação para a resistência social, como espaço de movimento dialético que permite a reconciliação da experiência crítica e reflexiva. Desse modo, estará cumprindo o seu compromisso de emancipação social, por meio da autorreflexão de sua arte, reinventando, assim, as linguagens tecnológicas na educação. 
No limite da instrumentalidade, a liberdade tão almejada só passa a ser possível, na ótica de Adorno (1995), se o pensamento for autorreflexivo e capaz de revitalizar a formação crítica dos sujeitos. Ao compreenderem a lógica instrumental presente nas tecnologias midiáticas que definem critérios de ação e comunicação, os sujeitos terão condições de desfrutar dos espaços de interação e informação, mediando a própria constituição subjetiva da realidade com discernimento formativo.

O estranhamento do sujeito com relação à realidade promovida pela indústria cultural está na experiência estética que contém no seu interior conteúdos sujeitos a novas interpretações, no esforço contínuo de abrir espaços para a ação enquanto linguagem crítica, sensível e criativa de construção da reflexão, que não é própria da racionalidade instrumental. A arte promove uma ação educativa de fazer com que os sujeitos se percebam em todos os sentidos e se reconheçam como singulares, criadores e diferenciados.

A recuperação do processo formativo que religa autonomia e contingência corresponde a uma educação crítica e tendencialmente subversiva do aprendizado aberto à elaboração da história e ao contato com o outro diferenciado. Adorno pauta sua crítica na impossibilidade de as pretensões de racionalidade absorverem a totalidade do real, tomando uma inflexão próxima ao pensamento de Benjamin, ao se preocupar com o papel da arte na transformação da consciência histórica.

Dessa forma, a relação com a tecnologia deve diferenciar-se da rapidez do consumo e da maquinaria do mundo, pois os modelos predefinidos dos sistemas operacionalizadores do ensino controlam o tempo e impedem a imaginação necessária ao próprio agir formativo. Há uma paradoxal confiança adorniana (1992b) na relação dialética da experiência crítico-formativa, uma vez que as categorias técnica e expressiva, teoria e práxis, estão relacionadas às condições históricas. Segundo Adorno (1992b, p. 203), “o sujeito devolvido a si mesmo, separado do seu outro por um abismo, seria incapaz de ação”, pois o bloqueio da experiência formativa faz com que a prática seja "danificada e, por isso, ansiada, desfigurada, desesperadamente supervalorizada”. De acordo com Tiburi (2005, p. 200):

\footnotetext{
[...] a importância da arte para a autocrítica da teoria reside no fato de que esta seria a face denunciatória de uma injustiça feita à natureza e condensada na teoria e na racionalidade, que absolutiza o conceito e condena a verdade a um aparecer previamente estabelecido, oposto frontalmente ao aparecer da arte.
}

A arte apresenta resistência à objetificação adotada pelo conceito pedagógico, bem como possibilita, no elemento expressivo, o caráter 
autoformativo e libertador da educação, que a razão instrumental reprimiu. A arte é autônoma e tem um caráter ambíguo exatamente porque tenta se assemelhar à realidade, fazendo-se diferente, sendo aparência e denúncia da realidade (criticando a própria sociedade a que tenta se assemelhar). O desenrolar de uma educação como experiência formativa pressupõe o reconhecimento do sentido da expressividade da arte na pluralidade conceitual, na contradição das formas de vida e no reconhecimento da alteridade pedagógica. A educação torna-se vazia e sem sentido quando não são preservados o exercício da crítica estética e a capacidade de problematizar o mundo, para contrapor os limites da formação tecnológica acelerada, em favor de uma reeducação linguístico-expressiva. Para efeito de qualificação da argumentação, percebe-se que a reconstrução da ação pedagógica como esfera de valor estético-expressivo conectado ao âmbito complexo da evolução das imagens e linguagens do mundo não deve excluir a hipótese de ser analisada como um processo mimético de aprendizado. Isso porque o reduto do comportamento mimético é onde o "sujeito expõe-se ao seu outro", trazendo à luz as especificidades do objeto (não pela sua assimilação ou redução), para fazê-lo falar através da linguagem mimética e do conteúdo expressivo das obras de arte (ADORNO, 1992a, p. 89). Esse posicionamento traz reflexos divergentes, pois a dimensão estética, segundo as palavras de Adorno (1992a, p. 501), “mostra antes que, até hoje, nenhuma racionalidade foi total, nenhuma foi em pleno benefício dos homens, das suas virtualidades, da natureza humanizada”.

$\mathrm{Na}$ escola, as tecnologias digitais, como mais uma mercadoria inserida no contexto da indústria cultural, prometem oferecer um ensino organizado, prático e racional. Mas fragmentar o conhecimento pela mera informação (enquanto comunicação abstrata, separada da relação intersubjetiva) incapacita o sujeito de compreendê-lo de maneira global, incluindo pensar sobre as causas, os processos, as linguagens, as consequências, os contextos de nosso ser em diálogo. A quebra da visão de totalidade impede a ação reflexiva de uma educação emancipadora que permite conduzir com dignidade o próprio conhecimento e os canais de comunicação da cultura. O choque entre as possibilidades oferecidas pelas tecnologias, diante do caráter incerto e frágil das fronteiras do conhecimento (efeito combinado das tecnologias da informação, redes, biotecnologias, nanotecnologia), e as lógicas da moeda e do poder vai continuar causando conflitos, em termos tecnocientíficos, como processo de desumanização. Contudo, a estética é essencial para que o jogo da compreensão seja construído através da navegação eletrônica daquele que a experimenta, provocando um estado de busca pelo saber e abrindo caminho para o inesperado e o diferente, que podem vir a ser um movimento para novos sentidos da aprendizagem. As artes levam-nos à dimensão estética da existência e, conforme o adágio que 
diz que a natureza imita a obra de arte, elas nos ensinam a ver o mundo esteticamente, a tratar problemas na experiência de reeducação interfronteiras que interliga saberes criativamente. Para atuar em termos de experiência compartilhada, as pessoas precisam de liberdade dos vínculos meios-fins, pois o objetivo não é só o conhecimento, ou a ocupação despreocupada, mas a resistência à massificação e à reificação humana. A ação educativa numa perspectiva estético-expressiva teria o mérito de abrir possibilidades de interpretação de tendências, um espaço alternativo para diferentes perspectivas de olhar para a realidade, bem como um movimento crítico de construção de intersubjetividades (reconhecimento do outro nas sutis matizes de diferenças e singularidades).

\section{EDUCAÇÃO: O ÚLTIMO REDUTO DA ARTE?}

A experiência estética possibilita o entrelaçamento de mito e racionalidade, atribuindo novos sentidos para a própria racionalidade (TREVISAN, 2000). Nesse sentido, a racionalidade da ação educativa passa a ser compreendida como uma racionalidade de potencial expressivo, articulada aos elementos estético-formativos, em contraposição a uma razão apenas técnico-instrumental. Nesse processo, a racionalidade estética abre possibilidades aos professores para despertarem novas aprendizagens e criarem obras de arte verdadeiramente concretas e enraizadas nos elementos da realidade, antagonistas da cultura industrial e da manipulação, para pensarem mais severamente sobre as correlações em termos de integração técnica, enquanto algo produzido na união de ação e reflexão pedagógica (ADORNO, 1992a). Essa ideia se alinha ao que Adorno (1992a, p. 542) chama de multiplicidade de objetos, que é despertada pelo próprio comportamento estético em seus choques e contradições, a saber: "porque o elemento enigmático da arte se articula apenas nas constelações de cada obra em virtude dos seus procedimentos técnicos é que os conceitos são não só a dificuldade de sua decifração, mas também a sua oportunidade".

Trata-se de indicar a noção de expressividade como a linguagem da obra de arte que pode proporcionar uma recuperação do potencial formativo das tecnologias nos processos educacionais. A educação percebida na expressividade da estética recupera a base comunicativa do conceito de formação, conforme defende Habermas (1992, p. 119):

\footnotetext{
A experiência estética não renova apenas as interpretações das necessidades, à luz das quais percebemos o mundo; interfere, ao mesmo tempo, também nas explicações cognitivas e expectativas normativas, modificando a maneira como todos esses momentos remetem uns aos outros.
} 
Somando-se a isso, Adorno considera que a arte não é exatamente oposta ao pensamento sistemático, mas oferece-lhe um modelo de recepção sensível à desconstrução da teoria pela arte; no entanto, permanece irrealizável em sua plenitude, pois continuará a viver dentro de seu outro (na arte).

Para Adorno (1992a), uma realidade que não se oferece como total a quem procura conhecê-la mantém apenas vestígios e ruínas de que um dia venha a se tornar uma realidade correta e justa. O autor compreende a crítica social marxista a partir do domínio da estética, formando assim o medium do processo de autoconstituição humana, como possibilidade de repensar o nosso tempo para transformá-lo. O legado adorniano na análise da transformação histórica da subjetividade está colocado "em cena para além dos termos da crise do sujeito existencial" (TIBURI, 2005, p. 124). Mas é no campo do heterogêneo que a dialética negativa adorniana leva o conceito ao encontro do seu elemento ético-estético na dinâmica da educação após Auschwitz. A partir do enfoque estético, anuncia um novo sentido da formação (enquanto expressão pela imaginação de nosso aprender o mundo pelas sensações), assinalando, no horizonte formativo, a compreensão da própria educação na totalidade da vida sensível. Adorno (1993, p. 69) defende que o processo de constituição humana é caracterizado pelas diferenças e pressupõe elementos emocionais, pois “o conhecimento se dá numa rede onde se entrelaçam prejuízos, intuições, inervações, autocorreções, antecipações e exageros, em poucas palavras, na experiência, que é densa, fundada, mas de modo algum transparente em todos os seus pontos”. Tal conhecimento é atravessado por marcas sociais, estéticas, éticas, técnicas, políticas, conjugando em sua estrutura um certo sentido formativo.

Adorno (1992a) vê na formação estética uma via de refúgio e reflexão diante de um mundo imperfeito (mundo da imersão na cultura industrializada, da incompreensão da arte e do estreitamento da cultura em semicultura), ${ }^{9}$ uma práxis socialmente apresentada como antítese da sociedade, para a revolução da própria vida, através do conectar-se às outras obras no processo social que pode ser decifrado na mediação técnica da arte (em devir formativo). Nesse contexto é que surge a possibilidade de repensar as tecnologias na educação do ponto de vista do empobrecimento das formas de produção e recepção, através da reconstrução estética de seus usos na educação, transformando seus afastamentos do contexto vital em novas possibilidades de interação social.

Talvez o potencial crítico da arte interligado com a tecnologia questão, ver: ADORNO Theodor W. Teoria da semicultura. Tradução de Newton Ramos-de- Oliveira. São Carlos: Editora UFSCar, 1992 na educação estaria, para Adorno, na reflexão crítica e na capacidade de expressão do inusitado e do inventivo. Na cultura de massas, o sujeito se torna alienado e descartável e, de certa forma, converge para a uniformização da percepção e da linguagem. Daí que o que está em jogo no significado da arte e da tecnologia são as ressonâncias e as reconstruções, a 
partir de seu próprio movimento mimético, ou seja, da relação intersubjetiva que se estabelece na singularidade da própria experiência social. Segundo Adorno, a arte torna-se social (reconhecimento do apreender na relação do sujeito com o mundo) no momento em que adota uma postura eminentemente crítica, contraditória e autônoma, superando a ingênua instrumentalidade e os efeitos nefastos de relações destituídas da capacidade de reflexão sobre o acúmulo de informações.

Adorno (1992a) busca na obra de arte uma via alternativa para enfrentar as "ilusões" da identidade (conceito petrificado daquilo que define as coisas), sem renunciar ao próprio conceito. Em Adorno (1992a), a experiência estética reside na exposição do sujeito ao impulso mimético, que traz a promessa de uma felicidade sem poder, sem instrumentalização, porque não se traduz na imitação, mas se amplia, inclusive, na racionalidade da própria obra de arte. Para Barbosa, "A mímesis significa, portanto, a força da expressividade da racionalidade imanente à própria configuração da obra de arte” (1996, p. 59). No mimético, está em jogo a autorreflexão da racionalidade na dinâmica de imbricação entre razão e sensibilidade, empatia e imitação, pensamento e corpo, sujeito e objeto, dependência e autonomia, arte e técnica, como consciência de inacabamento humano e capacidade de reinventar o mundo, que não anula as diferenças linguísticas e a necessidade de crítica e problematização pedagógica.

A tentativa de resgate do elemento expressivo da razão e o próprio desenvolvimento de instâncias críticas, sensíveis e emancipatórias tornam-se possíveis mediante uma práxis pedagógica comprometida com a formação de sujeitos artísticos que saibam interpretar o mundo com o fortalecimento da intersubjetividade, para fazer frente às perturbações do mundo globalizado, com seus imperialismos e injustiças sociais. A própria expressividade tem reconhecimento explícito na objetividade social, constituinte do humano, que motiva o olhar e realiza o diagnóstico da época, marcado pela dominação cultural planejada.

\section{CONSIDERAÇÕES FINAIS}

A investigação aponta que, para enfrentar uma sociedade baseada no mito da produtividade (que precisa de sujeitos pela metade, fiéis executores, diligentes reprodutores, dóceis instrumentos sem vontade própria), são necessários impulsos revisionistas dos movimentos conceituais e artísticos, bem como agentes criativos e transformadores, que saibam usar sua imaginação, sua sinceridade, sua autenticidade, sua espontaneidade para atuar no mundo em termos de reconstrução técnico-estética. Nos desafios de teor formativo sobre a estética, está implícita a capacidade de "reaprender a educar”, associada à aprendizagem 
permanente e à possibilidade de repensar e transformar a realidade, em relação com o outro na multiplicidade própria da vida.

A arte hoje ressurge como possibilidade de ação, manifestação, indignação e proposição diante das ações superficiais de uma cultura massificada e resistente à própria comunicação e à experiência estético-performativa. Essa consideração está muito além do abstracionismo pedagógico e de uma postura passiva ou receptora de ensino, mas inova intersubjetivamente, recupera o entusiasmo do agir pedagógico e perturba expressivamente a rotina docente, como um círculo de cultura (diria Freire) e de mudança. A defesa é de um sujeito participativo, reconstrutivo, que aprende com a multiplicidade de desafios e busca a autonomia decisiva na experiência estética, de integração do outro na esfera pública aberta de diálogo com outras autonomias na unidade de contrários, para além de sagacidades individuais. As tecnologias da comunicação não dispensam os sujeitos da força libertadora da reflexão e de um pensamento insatisfeito (de espanto), ligado ao diálogo com a práxis vital e a arte, como um impulso para a alteridade.

Desse modo, entendemos que os campos de conhecimento da linguagem da arte contêm elementos que subsidiam processos pedagógicos de reconhecimento estético necessário à formação e à reelaboração dos recursos tecnológicos. A arte pode contribuir para desinstalar conceitos fixos, impostos, deixando aparecer a imagem em movimento, efeitos das rupturas e descontinuidades de linguagens. Com Adorno, apostamos numa concepção de formação crítica que propicie elementos de integração artística e propositiva dos artefatos tecnológicos digitais à prática educativa, que hoje trazem itinerários e incursões para descolonizar e desalienar a reflexão sobre a conexão socialmente reconhecida. É preciso avançar no sentido de tecer um diálogo mais efetivo sobre os elementos e contradições de aprendizagem que as linguagens expressivas veiculadas pelas tecnologias digitais trazem e despertam. Em vista disso, manter o aspecto heterogêneo das tecnologias na educação como algo de natureza estética - radicalmente outro - mantém uma resistência ao imediato como contraponto ao caráter totalizante das amarras do mercado em sua lógica utilitarista e paralisante do aprender social. Por conseguinte, viabiliza o diálogo multicultural de correlação dialética entre as mudanças dos objetos, a alteridade e a pluralidade humana, de forma que a educação possa reaprender os diferentes sentidos do processo formativo pela dimensão crítico-estética com força propulsora para pensar a realidade movente. 


\section{REFERÊNCIAS}

ADORNO, Theodor. Teoria estética. Tradução de Artur Mourão. 1. ed. Lisboa: Edições 70, 1992a.

ADORNO, Theodor. Anotações sobre teoria e prática. In: RAMOS-DE-OLIVEIRA, N. Quatro textos clássicos. Tradução de Newton Ramos-de-Oliveira. São Carlos: UFSCar, 1992b. Publicação interna.

ADORNO, Theodor. Minima moralia: reflexões a partir da vida danificada. Tradução de Artur Morão. Lisboa: Edições 70, 1993.

ADORNO, Theodor. Educação e emancipação. Rio de Janeiro: Paz e Terra, 1995.

ADORNO, Theodor. O fetichismo na música e a regressão na audição. In: ADORNO, Theodor. Textos escolhidos. São Paulo: Nova cultural, 1996. p. 65-108.

ADORNO, Theodor. Dialética negativa. Tradução de Marco Antonio Casanova. Rio de Janeiro: Jorge Zahar, 2009.

BARBOSA, Ricardo C. Dialética da reconciliação: estudo sobre Habermas e Adorno. Rio de Janeiro: Uapê, 1996.

BENJAMIN, Walter. A obra de arte no tempo de suas técnicas de reprodução. In: BENJAMIN, Walter; ADORNO, Theodor; GOLDMAN, Lucien. Sociologia da arte. Rio de Janeiro: Zahar, 1969. v. 4.

BENJAMIN, Walter. Experiência e pobreza. In: BENJAMIN, Walter. Magia e técnica, arte e política: ensaios sobre literatura e história da cultura. 7. ed. São Paulo: Brasiliense, 1994. p. 114-119.

GADAMER, Hans-Georg. Elogio de la teoría: discursos y artículos. Tradução de Anna Poca Casanova. Barcelona: Península, 1993.

GOERGEN, Pedro L. A crítica da modernidade e a educação. Pro-posições, Campinas, v. 7, n. 2, p. 5-28, jul. 1996.

HABERMAS, Jürgen. Modernidade: um projeto inacabado. In: ARANTES, O.; ARANTES, P. Um ponto cego no projeto moderno de Jürgen Habermas. São Paulo: Brasiliense, 1992.

JAEGER, Werner. Paidéia: a formação do homem grego. 3. ed. São Paulo: Martins Fontes, 1995.

MARTINI, Rosa Maria F. Reencantar a ação educativa, um empreendimento possível? Reflexão e Ação, Santa Cruz do Sul, v. 13, n. 2, p. 15-21, jul./dez. 2005.

TIBURI, Márcia. Metamorfose do conceito: ética e dialética negativa em Theodor Adorno. Porto Alegre: Editora da UFRGS, 2005.

TREVISAN, Amarildo Luiz. Filosofia da educação: mímesis e razão comunicativa. Ijuí, Editora da Unijuí, 2000.

\section{ELAINE CONTE}

Doutora em Educação pela Universidade Federal do Rio Grande do Sul

- UFRGS -, Porto Alegre, Rio Grande do Sul, Brasil; professora do Centro Universitário La Salle - Unilasalle -, Canoas, Rio Grande do Sul, Brasil elaine.conte@unilasalle.edu.br

\section{CATIA PICCOLO VIERO DEVECHI}

Doutora em Educação pela Universidade Federal de Santa Catarina - UFSC -, Florianópolis, Santa Catarina, Brasil; professora da Universidade de Brasília - UnB -, Brasília, Distrito Federal, Brasil catiaviero@gmail.com 